\title{
What makes organic agriculture move - protest, meaning or market? A polyocular approach to the dynamics and governance of organic agriculture
}

\author{
Hugo F. Alrøe* \\ Danish Research Centre for Organic Food and Farming (DARCOF) \\ PO Box 50, DK-8830 Tjele, Denmark \\ E-mail: hugo.alroe@agrsci.dk \\ ${ }^{*}$ Corresponding author
}

\author{
Egon Noe \\ Department of Agroecology \\ Danish Institute of Agricultural Sciences, \\ PO Box 50, DK-8830 Tjele, Denmark \\ E-mail: Egon.Noe@agrsci.dk
}

\begin{abstract}
Many different actors have hopes and aspirations for the future of organic agriculture. They have different perspectives on organic agriculture with different understandings of what it is and what makes it move. Each perspective entails a certain understanding of organic agriculture featuring certain concepts and values and a particular logic or rationality. It is important to acknowledge this heterogeneity when investigating the dynamics and governance of organic agriculture. We suggest a polyocular approach that facilitates a comprehensive and balanced understanding of organic agriculture by enabling us to handle different perspectives reflexively. To illustrate this approach we describe three significant perspectives on organic agriculture based on protest, meaning and market. No perspective is the 'right' one and, we claim, different perspectives on organic agriculture cannot be merged to one. We hope that polyocularity as a general analytical tool, and the three specific perspectives, will be helpful in understanding the future development of organic agriculture and how it may be influenced.
\end{abstract}

Keywords: organic farming, regulation, perspectives, reflexive, actor network, semiotics, conventionalisation, values.

Biographical notes: Hugo Fjelsted Alrøe is a Senior Scientist at the Danish Research Centre for Organic Food and Farming. He holds a graduate degree in horticulture and a Ph.D. in systemic research methodology and ethics from the Royal Veterinary and Agricultural University, Copenhagen. His main research interests are in philosophy of science with a focus on crossdisciplinary research, research communication, the role of reduction and values and the systemic involvement of science in its subject areas; systems theory; semiotics; and ethics and value inquiry in relation to sustainability, precaution, ecological justice and organic agriculture. He has written numerous research articles in these areas and recently co-edited the book "Global Development of Organic Agriculture: Challenges and Prospects". Currently, he is manager of a work package on identifying and integrating values in the EU research project "Organic Revision" that is to support the revision of the EU regulation on organic agriculture.

Egon Noe is a Senior Scientist at The Department of Agroecology at the Danish Institute of Agricultural Sciences (DIAS). He holds a Ph.D. in rural sociology from the Royal Veterinary and Agricultural University in Copenhagen. His main field of interest is sociology of farm management and decision-making. 


\section{Introduction}

Organic agriculture has shown rapid growth and dynamic developments in recent years (Willer and Yussefi, 2005). Due to this success there are now many hopes for the future of organic agriculture. Many different actors, such as policy makers, farmers, small agri-businesses, idealists, researchers, agri-food corporations, supermarkets and consumers, seek to influence the future of organic agriculture in accordance with their goals. However, these actors have different views of what organic agriculture is and what makes it move ${ }^{\mathrm{i}}$.

Along with the recognition of the successes of organic agriculture in terms of area under organic management, market shares, percentages of food consumption and contributions to local economies and public environmental policy goals, there is considerable disturbance and debate about some of the trends and patterns in the development of modern organic agriculture - such as modernisation, institutionalisation, globalisation, functional differentiation, dis-embedding from local systems, enrollment in mainstream agri-food corporations, conventionalisation, industrialisation, professionalisation, intensification and specialisation.

In particular, there has been a lively debate among practitioners and academics on whether and to what extent there is a trend towards 'conventionalisation', where organic agriculture (farming, processing, trade etc.) becomes more like conventional (e.g., Guthman, 2004; Campbell and Liepins, 2001; Hall and Mogyorody, 2001; Lockie and Halpin, 2005). Or, more specifically, whether there is a (risk of) bifurcation into a threatened, 'deep' form of organic and a prolific, more shallow 'Organic Lite' that is more akin to conventional agriculture (Guthman, 2004). The debate has focused primarily on whether such conventionalisation is inevitable or universal due to the general mechanisms of agro-industrialisation - or, in other words, whether growth is possible without loosing the core values - and the implications of this for the transformative potential of organic agriculture. Lockie and Halpin (2005: 285) state that "the package of economic and ideological changes associated with 'conventionalisation' are not structural inevitabilities,” and point out that there has been less debate on what conventionalisation actually is.

In line with Lockie and Halpin (2005: 287), we do not think that a binary division between growth, market, globalisation and industrial production on the one ('bad') side and values, localness and artisanal production on the other ('good') side is a very fruitful way to approach the heterogeneous trends and patterns in the development of organic agriculture. The answers to when and where growth, market, globalisation, industrialisation and conventionalisation are problematic, or unproblematic, are not given beforehand, and, we claim, the answers will depend on what perspective is used.

Lockie and Halpin (2005: 285) further suggest a “need to re-theorise 'conventionalisation' in a manner that recognises more explicitly the role that such concepts play, not just in describing and/or explaining, but in attempting to shape relations of production and consumption.” This points to the reflexive question of how the conventionalisation debate affects the dynamics and governance of organic agriculture: the dynamics of the organic movement, the regulation of organic practices, the marketing and consumption of organic products, and the potential role of organic agriculture in addressing policy issues on environment, food security and health. The actor(network)s of organic agriculture are 'interactive kinds' (Hacking, 1999: 103-8) or, more precisely, 'self-reflexive kinds' that rethink themselves in response to research descriptions, and such circular, 
systemic effects need to be taken into account when doing research in organic agriculture (Alrøe and Kristensen, 2002).

In this paper, we investigate the preconditions for answering contested questions on the dynamics and governance of organic agriculture such as those above, though not restricted to the issues of the conventionalisation debate. This paper springs from a research project to support development of the EU regulation on organic agriculture, Organic Revision. Here the main questions are how organic regulations - a key element in the governance of organic agriculture - can influence the development of organic agriculture, and how the regulations can be developed in light of this. ${ }^{\text {ii }}$ Since we merely point out some preconditions for answering such questions here, this is a philosophical investigation that concerns the basis for empirical sociological research, and not a sociological investigation or a review of sociological research.

We suggest that a polyocular approach will facilitate a comprehensive and balanced understanding of organic agriculture by enabling us to handle different perspectives reflexively - and that this will be helpful in various discourses on the future course of organic agriculture and how it may be influenced. In the following, we first briefly explain what we mean by a polyocular approach and why we think it is needed. Then we outline a specific application of the polyocular approach in form of three perspectives on organic agriculture, which we think are useful to observe in relation to current issues of debate: organic agriculture seen as a protest against conventional, as a system based on its own meaning, and as a market opportunity .

\section{Why polyocular?}

"Perspectives may be understood broadly as perceptual and conceptual orientations to a situation with a view to acting within that situation” (Martin, 2005: 231).

The term 'polyocular' is formed as an extension of 'binocular'. It literally means to use many perspectives on the same thing - not only to see more aspects, but also to gain insights from the differences between them in the same way that binocular vision reveals a new dimension of

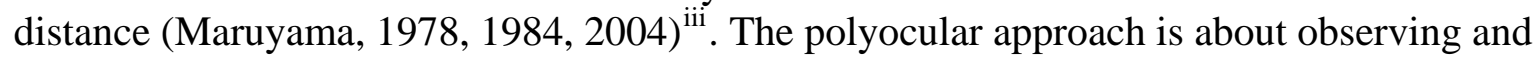
handling different perspectives on something. It builds on a thoroughly semiotic understanding coupled with a systemic conception of cognition and the concept of reflexiveness.

Different perspectives on organic agriculture can be identified, we claim, where each perspective entails its own view of what kind of object organic agriculture is; what its environment is; what its trajectory and dynamics are; and how it can be influenced. And each perspective entails a certain understanding of organic agriculture featuring certain concepts and values and a particular logic or rationality. We claim that there is no one right perspective that fully reveals organic agriculture; that each perspective offers some insight on organic agriculture; that it will always be possible to take on a new perspective; that one may hold different perspectives in succession; and that the different perspectives cannot, in general, be merged to one. But this does not mean that any perspective is as useful as any other for some purpose; or that a better, or fuller, or more balanced, or more subtle understanding cannot be approached. If we are to be able to understand how different actors or actor-networks (consumers, producers, processors, retailers, NGOs, agri-food corporations, certification bodies, financing bodies, researchers, governments, politicians, etc.) act in relation to organic agriculture and try to influence its course, it is crucial to observe their perspectives and take them into account. 
To back up the need for a polyocular approach, we will summarise some fundamental conditions for seeing something - or more precisely for cognising an object in the sense of the coordinated, systemic processes of observing/perceiving, (inter)acting, and understanding/representing (see Alrøe, 2000; cf. also Martin, 2005: 233ff). The formulation of these conditions demands that we are a little more precise about what we mean by 'something' or 'object'. Using the semiotic language of Charles S. Peirce, as illustrated in Figure 1, we need to distinguish between the immediate object, the object as we see and understand it $^{\text {iv }}$, and the dynamical object, the object in itself, which our representation refers to but which is not fully captured in the immediate object (see Noe et al., 2005; Noe and Alrøe, 2006).

The following two conditions for cognition, which we will elaborate below, are fundamental in the sense that they cannot be overcome, and as such they substantiate our call for polyocularity:

1. What we see depends on how we see it - and the same thing may therefore be seen in different ways.

o Any cognition is necessarily a reduction since it is based on a specific context.

o Any dynamical object has a surplus of possibilities for cognition - there is no complete cognition.

2. We cannot be sure that we see the same thing - even though we say we do.

o A name or a description creates different interpretations or understandings of different immediate objects for different people - or for different perspectives.

o Immediate objects do refer to dynamical 'objects in themselves', and dynamical objects 'strike back' in our interaction with them,

o but no one of the immediate objects as they are represented in the various perspectives is the same as the dynamical object in itself.

\subsection{First condition: What we see depends on how we see it}

Any cognition is necessarily a reduction since it is based on a specific context. Niels Bohr defined 'phenomenon' as including the apparatus that is used to observe the phenomenon. He advocated the exclusive application of the word phenomenon to refer to the observations obtained under specific circumstances, including an account of the whole experimental arrangement (Bohr, 1985: 27). In the language of Peirce, Bohr's 'phenomenon' is a term for the immediate object with its semiotic and interpretational context. We generalize Bohr's definition to include the broader cognitive context, entailing not only the observational context, but also the intentional and societal levels of context (see Table 1). This means that objectivity is only possible in form of 'reflexive objectivity', where the cognitive context is reflexively observed and included in the scientific communication (see Alrøe and Kristensen, 2002). The condition that any cognition depends on a context also means that we may see the same thing in different ways: Any dynamical object has a surplus of possibilities for cognition - there is no complete cognition.

According to Bohr it is not possible to comprehend the evidence of quantum phenomena, obtained under different experimental conditions, within a single picture (Bohr, 1949). The evidence from different experiments must be regarded as complementary in the sense that only the totality of phenomena will exhaust the possible information about the atomic objects. The complementary views of light and electrons as both particles and waves are well known. In the same sense, we argue that when we see organic agriculture as a certain kind of object, we also already employ a certain perspective - the epistemological framework conditions what the observer perceives. There is no hope of holism, so to speak, no hope in general that different perspectives can be merged to 
one, no hope to find one complete and accurate representation of a complex reality such as organic agriculture (see Noe et al., 2005).

\subsection{Second condition: We cannot be sure that we see the same thing}

There is a long way from communicating about something to that thing in itself. As Knorr Cetina (2001: 184) puts it: "naming, in the present conception, is a way to punctuate the flux, to bracket and ignore differences, to declare them as pointing to an identity-for-a-particular-purpose.” When we talk about organic agriculture, using "organic agriculture" as a name or even using a more detailed description, this will create different interpretations or understandings that stand for different immediate objects for different people - or for different perspectives. This is the lesson of Peirce's semiotics (see Figure 1) and the idea is radicalised by Luhmann (1995: 143): “The fact that understanding is an indispensable feature in how communication comes about has far-reaching significance for comprehending communication. One consequence is that communication is possible only as a self-referential process"(emphasis in original).

The immediate objects that are represented in the different perspectives do refer to objects in themselves, and dynamical objects do 'strike back' in our interaction with them (cf. Latour, 2000), but none of the immediate objects are the same as the dynamical object in itself.

When we refer to dynamical objects such as 'organic agriculture', we must acknowledge the paradox in wanting to speak directly about dynamical objects when all that we can represent are immediate objects. We may interact with the dynamical object through experiments, observations and practical, experiential interactions and in this way we can seek to establish that we "carve nature by its joints' in our representation of it, and that we actually refer to the same dynamical object when we want to do so. But this is never unquestionable. Different perspectives will often 'carve nature' in different ways and the 'epistemic world' or 'perspectival ontology' of any one perspective will never fully capture the dynamical world as it is.

The uncertain reference to 'organic agriculture' as a dynamical object adds to the complexity of pursuing a polyocular approach. Still, if we do not pursue it, we are left with the unfruitful task of arguing who is right without knowing from which perspective the arguments arise. Only some form of polyocularity will enable us to resolve conflicts between perspectives in order to better understand and influence the dynamics of 'organic agriculture'. Polyocularity is thus not only the basis for an empirical methodology for analysis, but also for an ethical methodology for handling conflicts (cf. Martin, 2005: 242f).

\subsection{Not groups, not discourses}

The polyocular approach differs from both 'ontological' and 'epistemological' approaches. 'Ontological' approaches to heterogeneity divide organic agriculture into different groups, such as the separation into those who want to remain close to the organic values and those who want to follow the call of the market. These approaches thereby conflate perspectives with actors or structures and tend to neglect the problematic issues and rationales that work across these divisions. 'Epistemological' approaches focus on what is written and said about organic agriculture. For example, discourse analyses focus on the dialectical aspects of texts and their social contexts and refrain from investigating the practical, intentional and observational contexts. They thereby tend to neglect the connection between discourses and practices and treat perspectives as merely discourses. Whereas the 'ontological' approaches presume a one to one relation between actors and interests in influencing organic agriculture, the 'epistemological' approaches have no tools for working with the connection between text and action. 
A perspective is not a group nor a discourse, but a way of seeing, reasoning and acting. The polyocular approach does not presume a one to one relation between actors and perspectives, and in line with Actor-Network theory it connects different kinds of relations, such as physical, nonsemiotic relations, biological, semiotic relations and intellectual, self-reflexive relations (see Noe and Alrøe, 2006). In this light it makes sense to say that perspectives on organic agriculture have a capacity to make it move, though it is probably more correct to say that perspectives form - enable and restrict - the ways in which it is influenced.

\subsection{Different kinds of perspectives}

Having argued the need to observe different perspectives in order to understand the heterogeneity of organic agriculture, we may ask what kind of perspectives to observe.

Magoroh Maruyama, the originator of the concept of polyocularity, investigated very general, cross-cultural 'epistemologies' or 'mindscapes' with different modes of thinking and reasoning (Caley and Sawada, 1994). At the same level there are many other attempts at working with 'world hypotheses', 'Weltanschauung' and various forms of 'worldviews', but these all seem of limited relevance to the heterogeneity of organic agriculture.

More concretely, scientific disciplines each have their own perspective on organic agriculture. This is especially true when there is a strong differentiation into separate disciplines, and here the polyocular approach can serve as a basis for multidisciplinary cooperation (Noe et al., 2005). Polyocular communication and cooperation on organic research is interesting and much needed, but in the present case we are interested in identifying the most influential perspectives that are shared by a range of different actors and not just found in a single discipline or within scientific circles. Such transdisciplinary perspectives on organic agriculture are outlined in few publications. Tybirk et al. (2004) describe three views of nature and relate them to different approaches to nature quality in organic agriculture. Verhoog et al. (2003) explore three aspects of the concept of naturalness related to three main approaches in organic agriculture. Halberg et al. (2006) use three perspectives on globalization and sustainable development to structure a synthesis on the challenges and prospects of organic agriculture. However, the first two focus on particular concepts, and the latter is too general to give insights into the internal dynamics of organic agriculture. In the following section we suggest three significant perspectives on organic agriculture that we find helpful in understanding the future development of organic agriculture and how it may be influenced.

\section{Three perspectives on organic agriculture}

Concepts such as protest, alternative, market, brand, ideology and religion have been used to characterise organic agriculture. In this section we outline three perspectives and their view of the structure, dynamics and governance of organic agriculture. The three perspectives are: organic agriculture seen as an alternative in opposition to the mainstream; organic agriculture seen as a selforganising system based on common organic values; and organic agriculture seen as a market opportunity. These three perspectives are constructed on the basis of collected experiences with organic research, practice and discourse. As will be clear from the previous section, we do not at all claim that no other perspectives can be found. As any other model, the three perspectives above are constructs that are generated to represent aspects of the world for certain purposes. But we think that these three perspectives are sufficiently distinct to capture much of the heterogeneity in what organic agriculture is and what makes it move, and that they can be used to get a more comprehensive and balanced understanding of the contested issues and questions that we discussed 
above. Proposing these three specific perspectives thus has a purpose in itself, but besides that we hope that the description of these perspectives can serve as an illustration of the polyocular approach and help initiate a discussion of it.

\subsection{The protest perspective: an alternative to conventional}

Organic agriculture is often characterised as a protest against modern industrialized and globalised agriculture similar to other protest movements against various aspects of modern society. In the protest perspective, organic agriculture is an alternative that is defined through its negation of conventional agriculture - and which is therefore inseparable from the mainstream, formed as it is by its dissociation from it. If the alternative becomes mainstream, the only options from this perspective are to give up or form a new alternative. ${ }^{\mathrm{v}}$ The environment of the alternative is always the mainstream and what makes organic agriculture move, the 'driving forces' so to speak, are certain aspects and developments of mainstream agriculture that are perceived as problematic.

It is in the nature of the protest that the reactions to mainstream developments are often conservative, trying to reverse some of the modern trends and, to some degree, recreate agricultural systems of the past. In this respect, the protest reaction is related to the principle of precaution, which seeks to avoid irreversible, harmful developments. Both can be seen to say "No!" to new trends and technologies. But while precaution can be a strong driving force in protests, protest as such can be against anything unwanted, not merely the unforeseeable and irreversible. The four well-known No!'s in organic agriculture are: no use of synthetic fertilizers, pesticides, or food additives, and (the more recent) no to genetically modified organisms.

Collective protest, such as in the movements on peace, nuclear energy, homosexuality, etc., is mostly a strategy to reform the mainstream, but protests may also lead to the realisation of alternative practices and organisations that coexist with the mainstream, as in the case of organic agriculture. From an outside point of view, organic farming is often seen as precisely that: an alternative to the conventional for public policy and consumer choice.

Usually, no distinction is made between the organic movement as a social movement or organisation and as a protest movement - protest is seen as an inherent element in the explanation of organic agriculture as a social movement. "Those engaged in the movement are involved in collective action focusing on conflicts, which are arranged around an oppositional contest over a particular social stake, in this instance food and farming. The final element of the movement is the use of protest ...” (Reed, 2005, emphasis in original; see also Michelsen, 2001b). In work on social movements in general there is a discussion of different models of social movements: 'resource mobilisation', 'political process' and 'collective identity' (e.g., Stoecker, 1995; Polletta and Jasper, 2001). Protest plays a role in all these models, but as Reed (2004: 39) concludes in his examination of rural protest movements: "The dominance of the identity as a concept around which social and protest movements mobilise belies the difficulties of actually constructing and realising a collective identity."

We think that a clearer picture can be gained by distinguishing two different perspectives on what is usually named 'organic agriculture as a social movement'. The positive identity of the alternative is not really visible from the protest perspective, which is based on negation of the mainstream, and we suggest that the positive identity of organic agriculture is better observed from the separate perspective on organic agriculture as a self-organising system based on its own meaning. 


\subsection{The logo-poietic perspective: a certain organic meaning}

Organic agriculture is often described as an ideology, or even a religion, and many within organic agriculture describe it as a movement with certain values, principles and goals. To characterise what kind of entity organic agriculture is in this perspective and what makes it move, we find it useful to regard it as a logo-poietic system or network. The term 'logo-poietic' is based on the notions of 'autopoiesis', the self-organisation and self-creation of cells and living organisms, and 'logo', a Greek word for meaning or meaningfulness borrowed from Viktor Frankl's logotherapy: logo-poiesis describes meaning as a self-organising principle (see Noe and Alrøe, 2005).

In the logo-poietic perspective, organic agriculture is a system that creates itself and holds itself together by the continuous reproduction of a certain organic meaning (or meaningfulness), expressed in shared worldviews, values, principles, goals, standards and practices. A particularly clear example of this self-creation and reproduction is the participatory process of rewriting the Principles of Organic Agriculture that was recently carried out by the International Federation of Organic Movements (IFOAM, 2005). Even though there are common basic values and principles, or rather, because of this, the logo-poietic system leaves room for a diversity of forms of organic agriculture, such certified and non-certified organic, biodynamic and organic/biological agriculture, etc.

As a self-organising system, organic agriculture is not dependent on mainstream agriculture in the way a protest movement is. The environment of the logo-poietic system is determined by the system itself. It is the 'Umwelt' or the 'epistemic world' as it sees it and interacts with it (see Alrøe, 2000). And mainstream actors, technologies and resources are enrolled into the system in ways determined by the system itself (cf. Noe and Alrøe, 2003, 2006). In this perspective, the driving forces that make organic agriculture move are not the external conditions but the internal processes of meaning. Influencing the future of organic agriculture therefore goes by way of influencing the reproduction of meaning within the system.

Key challenges for organic agriculture as a logo-poietic system are, on the one hand, how to grow and to mobilise new actors and technologies into the network of organic agriculture without loosing the internal coherence, the sense of direction, and the integrity of principles and practice. Here the formulation of basic principles and standards play an important guiding role. And, on the other hand, how the inclusion of organic agriculture into global markets, multinational corporations and agricultural policies will influence the reproduction of meaning in the movement - whether it will erode the principles and standards and, in effect, conventionalise organic agriculture. These challenges point to the third, quite different, but widespread perspective, which sees organic agriculture as a market opportunity.

\subsection{The market perspective: a niche}

Organic agriculture is often considered a part of the global market system like any other kind of special agricultural production. Here, 'market' not only denotes a section in society that organic agriculture has to cope with (Michelsen, 2001a: 10); it also denotes a way of thinking: a certain perspective on organic agriculture. In the market perspective, organic agriculture is a set of market opportunities and networks: a market niche based on standards that specify the special conditions for production and processing, certification and control, and branding of the products as alternative brands.

Hence, this perspective shares a focus on standards as a key element in organic agriculture with the logo-poietic perspective, but for different reasons. From the market perspective the focus is on 
segmentation, on the niche as such, and not necessarily on the specific meaning or protest involved - all that is required is to tailor the products to the unique needs of the segment and to speak the language of the target group.

The environment of organic agriculture as a market niche is the global market. Standards, certification and branding are primarily intended to define the market niche, to enable growth and invention, to avoid unfair competition, and to aid consumer recognition and choice. Driving forces in focus are differentiation from other brands, and consumer preferences and perceptions.

Key challenges from the market perspective are barriers to trade and the pressures from power relations in a globalised market. With regard to the latter, large-scale, effective production methods, sustained supply of uniform products, growth, and financial strength are important abilities. Finally, an important challenge is to maintain consumer trust and loyalty in a market environment where branding is a major factor and transparency is often considered a drawback for cost-efficiency.

\section{A polyocular view of current issues in organic agriculture}

Organic agriculture regarded as an alternative in opposition to the mainstream, a logo-poietic system based on organic values and principles, and a market niche are complementary phenomena and no single perspective exhausts what we can know about the dynamics and governance of organic agriculture. Figure 2 shows a polyocular view of organic agriculture based on these three perspectives. It is important to see that the polyocular view of organic agriculture is not a new first order perspective, which can replace the ones that it is observing. A polyocular view is possible only as a reflexive process of second order observation and communication on different perspectives (see also Noe et al., 2005).

An important implication of the polyocular approach is that it is not possible to communicate directly across different perspectives - or, rather, it is, but the communication will be error-prone and uncertain, because the concerns, concepts and logics of one perspective cannot be directly translated into a different perspective. Even if the same terms are used, they will often have different meanings in different perspectives. For example, concepts such as sustainability, globalisation, natural, animal welfare, necessary inputs, efficiency and organic have different meanings in discourses connected to different perspectives (e.g., Alrøe et al., 2006; Byrne et al., 2006; Verhoog et al., 2003; Tybirk et al., 2004; Alrøe et al., 2001). Only by observing and communicating the cognitive context of the concepts in the different perspectives, can a more balanced and subtle understanding be approached. In general, it is necessary to observe the cognitive context of different statements and include the perspective from which something is said in the understanding of what is said.

In the following sections we have made a first attempt at a polyocular description of selected current issues in organic agriculture, using the three perspectives that were described above.

\subsection{The relation to the mainstream}

A protest movement will always be more or less antagonistic towards what it is protesting against. The protest perspective has led to some very antagonistic relations indeed, not only in farming, but also in processing, retailing and science, resulting in flame wars (e.g., BFA, 2004) and lawsuits (e.g., COOP, 2005). Antagonistic relations can be barriers for the mainstream learning from the alternative and vice versa, for knowledge transfer, research cooperation, etc. 
Since the logo-poietic system rests on its own principles and values, it can exist independently of the mainstream and maintain a relatively flexible and unproblematic relation to conventional agriculture as an alternative option for farmers, businesses, consumers, etc. - a relation that features enrollment instead of antagonism. But there may be conflicts due to mainstream activities that inflict upon the practices of organic agriculture.

From a market perspective the existence of alternatives in the market is basically good for growth and trade and the relation is therefore fully unproblematic: organic agriculture is incorporated into mainstream business, or at least attempts are made to do so, though there may be conflicting interests in patenting, competition, marketing, etc. From the logo-poietic perspective, on the other hand, this incorporation does not necessarily incorporate the organic principles and the meaningfulness that they express, and threatens to erode the standards and practices of organic agriculture.

\subsection{Stability and viability}

From the logo-poietic perspective there is a built-in promise for stability and viability in organic agriculture, because of the focus on sustainability in the principles. The protest-based alternative has no independent coherence, stability, and viability - it rests on its opposition to the mainstream. If and when the mainstream improves on an issue of protest, the protest must move to another issue or die out. From a market perspective, the niche of organic agriculture may not be viable, but this is not essential. The market system does not depend on any particular segment or brand. There are always new segments to explore, new niches to enter and new brands to build by putting a new spin on what you are already doing.

\subsection{Growth and trade}

The market perspective supports the growth of organic agriculture by way of the market, and if this perspective is neglected by the organic actors, organic agriculture may remain a very small niche in terms of market share. From the logo-poietic perspective, growth or no growth is not a problem per se. Growth that helps pursue the principles and goals that organic agriculture is organised around, is good, but growth must not happen at the cost of the organic meaning (principles, values, goals, etc.). There is a fairly obvious risk that this may happen. Growth in modern agriculture is connected to industrialisation, intensification, specialisation, distant trade, commodification of hitherto commons, involvement of large agri-food corporations and externalisation of social and environmental costs. From the logo-poietic perspective, these are serious challenges to organic agriculture (see also Alrøe et al., 2006). From a protest perspective, growth of the alternative is inherently good as long as it retains its opposition to the mainstream. But there is an upper limit to how large an alternative can become without becoming the mainstream.

From a market perspective globalisation and free trade is good and unproblematic. Trade brings organic products beyond local markets to the many urban consumers of today's world. From the logo-poietic perspective the globalisation of organic agriculture is good in the sense that the organic meaning is spread around the globe. And certified trade can be an option for political consumers to participate in the reproduction of this meaning by way of their consumer choices. But there are also aspects of globalisation and growth that work against this very meaning (as outlined above) and which, in the case of certified trade, need to be counteracted by developing the standards and certification systems. 


\subsection{Conventionalisation of organic agriculture}

'Conventionalisation', in the sense that organic agriculture and conventional agriculture are becoming more alike, may happen in different ways. A: organic agriculture may move towards the conventional (larger farms, entering mainstream agro-food corporations, etc.); B: conventional actors may enter organic agriculture (presumably, at least initially, operating on another meaning with different values and logics); and C: the conventional may move toward organic agriculture (becoming more environmentally friendly, for instance).

From the logo-poietic perspective C is unproblematic and both A and B are fine - if and only if the meaning that organic agriculture is organised around can be maintained. From the market perspective $B$ is good (presuming that this entails professionalisation) and $A$ and $C$ are fine - if the differentiated brands can be maintained. From the protest perspective, it is bad that conventional and organic agriculture become more alike, no matter how it happens.

\subsection{Non-certified organic agriculture}

From the logo-poietic perspective, 'non-certified organic agriculture' (local, often traditional agriculture that is managed more or less in accordance with the principles of organic agriculture, but is not based on certification, trade and premium prices) promises an alternative development path in rural areas of low-income countries (Halberg et al., 2006). And non-certified organic agriculture is less prone to the market pressures connected to growth and trade, which threaten to erode the standards and practices of certified organic agriculture. From a protest perspective, non-certified organic agriculture may play the role of opposition as well as, or even better as, certified organic agriculture. From the market perspective, however, non-certified organic agriculture is not even visible - it cannot play any role in the global market. Anyhow, the promises of non-certified organic agriculture from a logo-poietic (or protest) perspective are still threatened by the global market and, for instance, the 'dumping' of cheap, supported food and feed from industrialised countries. These threats can only be avoided if non-certified organic agriculture is made visible to trade institutions.

\subsection{Purpose of standards and principles}

From the protest perspective, the purpose of standards and regulations is to specify the differences to the mainstream, such as 'no GMO'. This may also be useful from the market perspective as a way to define the market niche. The logo-poietic perspective, on the other hand, sees standards as a guide to assist the reproduction of a shared meaning. The basic values and principles, and the connection between principles and rules, is therefore of key concern here, whereas the market is only concerned with principles if they can be used for branding purposes. From the protest perspective, the opposition to conventional agriculture is value based, but it is the antagonism of the values that is in focus and not their development into ethical principles of action and alternative practices based on the meaning that they entail independently of the relation to the mainstream.

\section{Conclusions and prospects}

"The future is not an object of prediction or forecasting, but depends on our decision, design and action today" (Magoroh Maruyama in Caley and Sawada, 1994: 185)

Many different actors have hopes and aspirations for the future of organic agriculture, 
and there is a heated debate in relation to organic practices and regulations about some of the current trends. Different perspectives on organic agriculture are at play in this debate, with different understandings of what organic agriculture is and what makes it move.

To investigate this complex and heterogeneous situation and address the contested issues in modern organic agriculture, we need to be able to handle a plurality of perspectives. The polyocular approach is an analytical tool that enables us to do just that:

- No one perspective can show all there is to show about the dynamical object of 'organic agriculture', which has a surplus of possibilities for new perspectives and understandings.

- A polyocular view of organic agriculture is only possible as a reflexive process of second order observation and communication on different perspectives.

- Different perspectives may refer to 'organic agriculture', but it is uncertain whether they refer to the same dynamical object

- To establish a common reference (or demarcate references to different dynamical objects), we can interact with the object through common experiments, shared observations and practical experiences with concrete cases, etc.

- To fully understand a perspective, one must engage in it, or engage actors who are familiar with it, in a polyocular communication process.

- In such a process, it is necessary to include the perspective from which something is said in the understanding of what is said, and try to observe the full cognitive context.

- Some perspectives are more powerful than others in terms of status, rhetorics, etc. But for the polyocular approach to succeed, it is important to avoid the hegemony of one or a few perspectives and give all relevant perspectives a space.

- The polyocular view is something besides the perspectives observed, not a replacement. In general, there is no hope of establishing one, holistic, all-comprehensive perspective.

A perspective is not a group, nor a discourse, but a way of seeing, reasoning and acting. The polyocular approach does not presume a one to one relation between actors and perspectives, such as the approaches that divide organic agriculture into different groups of actors, and which therefore tend to neglect the problematic issues and rationales that work across these divisions. It is not restricted to the dialectical aspects of texts and their social contexts like discourse analyses, which thereby tend to neglect the connection between discourses and practices, but incorporates the practical, intentional and observational contexts. Perspectives on organic agriculture do have a capacity to make it move, and only some form of polyocularity will enable us to understand the different perspectives, and thereby help us approach a more balanced and subtle understanding of the dynamics of 'organic agriculture' and how it may be influenced.

We hope that you find the polyocular approach sufficiently interesting to react on it, protest against it, start using it, comment on the three perspectives and the examples that we have outlined, propose other ones, or in some other way enter into a reflexive, polyocular discourse on organic agriculture.

\section{Acknowledgements}

We thank Henk Verhoog, Helena Röcklinsberg, Chris Kjeldsen, Anne Mette Sørensen Langvad and three anonymous reviewers for the valuable comments they have given on an earlier version of this paper. The research underlying this paper is funded, in part, by the EU project Organic Revision (Contract no. FP6-502397). 


\section{References}

Alcântara, T. and de Alcântara, D.P. (2004) 'Development of local organic markets: The final letter', International workshop on alternative certification. Ecology \& Farming, No. 37. See further on <http://www.ifoam.org/about_ifoam/standards/pgs.html $>$.

Alrøe, H.F. (2000) 'Science as systems learning. Some reflections on the cognitive and communicational aspects of science’, Cybernetics and Human Knowing, Vol. 7, No. 4, pp.5778.

Alrøe, H.F. and Kristensen, E.S. (2002) 'Towards a systemic research methodology in agriculture: Rethinking the role of values in science', Agriculture and Human Values, Vol. 19, No. 1, pp.323.

Alrøe, H.F., Vaarst, M. and Kristensen, E.S. (2001) 'Does organic farming face distinctive livestock welfare issues? A conceptual analysis', Journal of Agricultural and Environmental Ethics Vol. 14, No. 3, pp.275-299.

Alrøe, H.F., Byrne, J. and Glover, L. (2006) 'Organic agriculture and ecological justice: Ethics and practice’, in: N. Halberg, M.T. Knudsen, H.F. Alrøe and E.S. Kristensen (Eds.) Global Development of Organic Agriculture: Challenges and Prospects. Wallingford: CABI publishing, pp.75-112.

BFA (2004) 'Organic industry rejects claims questioning its sustainability'. Press release 4 October 2004. <http://www.bfa.com.au/_files/Organic\%20industry\%20rejects\%204.10.04.pdf>

Bohr, N. (1949) 'Discussion with Einstein on epistemological problems in atomic physics', in P.A. Schilpp (Ed.) Albert Einstein Philosopher-Scientist. Evanton, IL: The library of living philosophers, pp.200-241.

Bohr, N. (1985) 'Kundskabens enhed [The unity of knowledge]', in Naturbeskrivelse og menneskelig erkendelse. Udvalgte artikler og foredrag fra årene 1927-1962. Rhodos, København, pp.19-39. [Danish version originally 1957. English version in The Unity of Knowledge, New York: Doubleday \& Co., 1955.]

Byrne, J., Glover, L. and Alrøe, H.F (2006) 'Globalisation and sustainable development: a political ecology strategy to realize ecological justice’, in N. Halberg, M.T. Knudsen, H.F. Alrøe and E.S. Kristensen (Eds.) Global Development of Organic Agriculture: Challenges and Prospects. Wallingford: CABI publishing, pp.49-74.

Caley, M.T. and Sawada, D. (1994) Mindscapes: The epistemologies of Magoroh Maruyama. Gordon and Breach Science Publishers.

Campbell, H. and Liepins, R. (2001) 'Naming organics: understanding organic standards in New Zealand as a discursive field', Sociologia Ruralis, Vol. 41, No. 1, pp.21-39.

Christensen, J. (1998) Alternativer - natur - landbrug [Alternatives - Nature - Agriculture]. Doctoral thesis. København: Akademisk Forlag,.

COOP Sweden (2005) Änglamarksmålet avslutat [The completion of the “Änglamark” law suit]. Pressmeddelande 2005-04-12. $<$ http://wpy.observer.se/wpyfs/00/00/00/00/00/05/8D/7F/wkr0001.pdf>

Giere, R.N. (2003) 'Perspectival pluralism. Forthcoming in Scientific Pluralism', Minnesota Studies in Philosophy of Science, Vol. 19. Preprint available at <http://www.tc.umn.edu/ giere/R\&Fpubs.html>

Giere, R.N. (2006) Scientific Perspectivism. Chicago: University of Chicago Press, forthcoming. Ch. 1 available at <http://www.tc.umn.edu/ giere/R\&Fpubs.html>.

Guthman, J. (2004) 'The Trouble with 'Organic Lite' in California: a Rejoinder to the 'Conventionalisation’ Debate’. Sociologia Ruralis, Vol. 44, No. 3, pp.301-316.

Halberg, N., Alrøe, H.F. and Kristensen, E.S. (2006) 'Synthesis: prospects for organic agriculture in a global context’, in N. Halberg, M.T. Knudsen, H.F. Alrøe and E.S. Kristensen (Eds.), 
Global Development of Organic Agriculture: Challenges and Prospects. Wallingford: CABI publishing, pp.343-367.

Hall, A. and Mogyorody, V. (2001) 'Organic farmers in Ontario: an examination of the conventionalisation argument', Sociologia Ruralis, Vol. 41, No. 4, pp.399-422.

IFOAM (2005) Principles of Organic Agriculture. International Federation of Organic Movements. Online at <http://www.ifoam.org/about_ifoam/principles $>$ and $<$ http://ecowiki.org/IfoamPrinciples>.

Knorr Cetina, K. (2001) 'Objectual practice’, in T.R. Schatzki, K. Knorr Cetina and E. Von Savigny (Eds.) The Practice Turn in Contemporary Theory, London: Routledge, pp.175-188.

Latour, B. (2000) 'When things strike back: a possible contribution of 'science studies' to the social sciences'. British Journal of Sociology, Vol. 51, No. 1, pp.107-123.

Lockie, S. and Halpin, D. (2005) 'The 'Conventionalisation' thesis reconsidered: structural and ideological transformation of Australian organic agriculture’, Sociologia Ruralis, Vol. 45, No. 4, pp.284-307.

Luhmann, N. (1995) Social systems. Stanford University Press, Stanford, California.

Martin, J. (2005) 'Perspectival selves in interaction with others: Re-reading G.H. Mead's social psychology’. Journal for the Theory of Social Behaviour, Vol. 35, No. 3, pp.231-253.

Maruyama, M. (1978) 'Endogenous Research and Polyocular Anthropology', in R. Holloman and S. Arutiunov (Eds.), Perspectives on Ethnicity. The Hague: Mouton Publisher.

Maruyama, M. (1984) 'Alternative concepts of management', Asia Pacific Journal of Management No. 1, pp.100-111.

Maruyama, M. (2004) ‘Polyocular vision or subunderstanding?’, Organization Studies, No. 25, pp.467-480.

Michelsen, J. (2001a) 'Recent development and political acceptance of organic farming in Europe', Sociologia Ruralis, Vol. 41, No. 1, pp.3-20.

Michelsen, J. (2001b) 'Organic farming in a regulatory perspective. The Danish case', Sociologia Ruralis, Vol. 41, No. 1, pp.62-84.

Noe, E. and Alrøe, H.F. (2003) 'Farm enterprises as self-organizing systems: A new transdisciplinary framework for studying farm enterprises?' International Journal of Sociology of Agriculture and Food, Vol. 11, No. 1, pp.3-14. Available online at $<$ http://orgprints.org/325>

Noe, E. and Alrøe, H.F. (2005) The challenge of management of multidimensional enterprises analysed from a logo-poietic perspective. Working paper, available online at $<$ http://www.agrsci.org/content/view/full/2178>.

Noe, E. and Alrøe, H.F. (2006) 'Combining Luhmann and Actor-Network Theory to see farm enterprises as self-organizing systems', Cybernetics and Human Knowing, Vol. 13, No. 1, pp.34-48. Postprint available online at <http://orgprints.org/324>

Noe, E., Alrøe, H.F. and Langvad, A.M.S. (2005) A semiotic polyocular framework for multidisciplinary research in relation to multifunctional farming and rural development. Paper presented at the XXI ESRS Congress, Hungary, August 22-27, 2005.

Polletta, F. and Jasper, J.M. (2001) 'Collective identity and social movements', Review of Sociology, No. 27, pp.283-305.

Reed, M. (2004) 'The mobilisation of rural identities and the failure of the rural protest movement in the UK, 1996-2001', Space and Polity, Vol. 8, No. 1, pp.25-42.

Reed, M.J. (2005) 'Turf Wars: the attempt of the organic movement to gain a veto in British agriculture’, forthcoming in M.J. Reed and H. Campbell. (Eds.) Organic Agriculture: A Sociological Perspective. Wallingford: CABI publishing.

Rueger, A. (2005) 'Perspectival models and theory unification', British Journal for the Philosophy of Science, No. 56, pp.579-594. 
Stoecker, R. (1995) 'Community, movement, organization: The problem of identity convergence in collective action’, The Sociological Quarterly, Vol. 36, No. 1, pp.111-130.

Tybirk, K., Alrøe, H.F., and Frederiksen, P. (2004) 'Nature quality in organic farming: A conceptual analysis of considerations and criteria in a European context', Journal of Agricultural and Environmental Ethics, Vol. 17, No. 3, pp.249-274.

Verhoog, H., Matze, M., Lammerts van Bueren, M. and Baars, T. (2003) 'The Role of the Concept of the Natural (Naturalness) in Organic Farming', Journal of Agricultural and Environmental Ethics, Vol. 16, No. 1, pp.29 - 49.

Willer, H. and Yussefi, M. (Eds.) (2005) The World of Organic Agriculture 2005: Statistics and Emerging Trends. IFOAM Publication, 7th ed. Online at <http://www.soel.de/oekolandbau/weltweit.html> 


\section{Figures and tables}

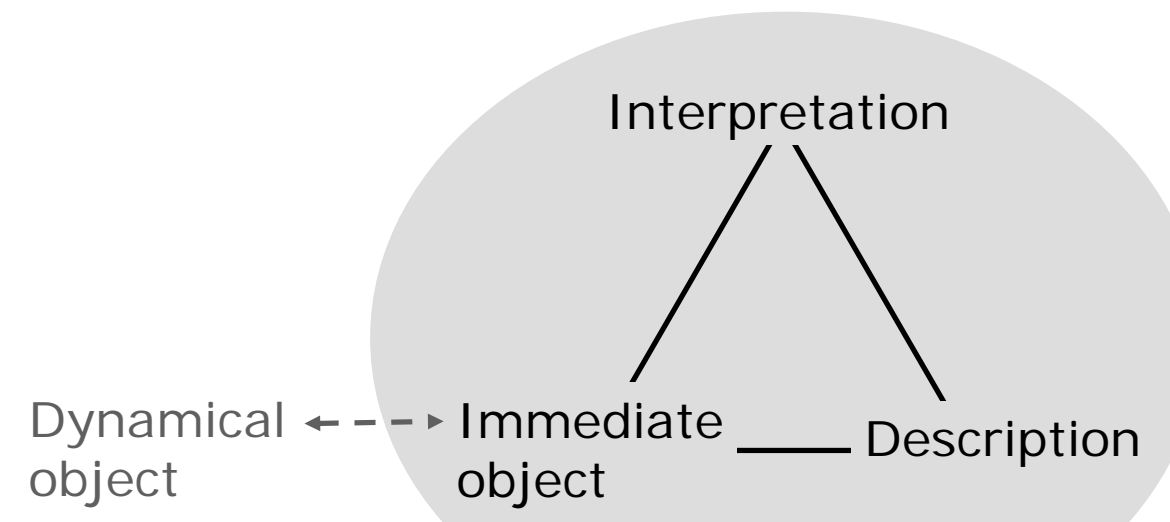

Figure 1.

A Peircean view of the semiotic relation between the triadic sign - description (representamen), interpretation (interpretant), and immediate object (the object as we see it) - and the dynamical object (the object in itself).
Dynamical
Perspectives
Polyocular
object approach

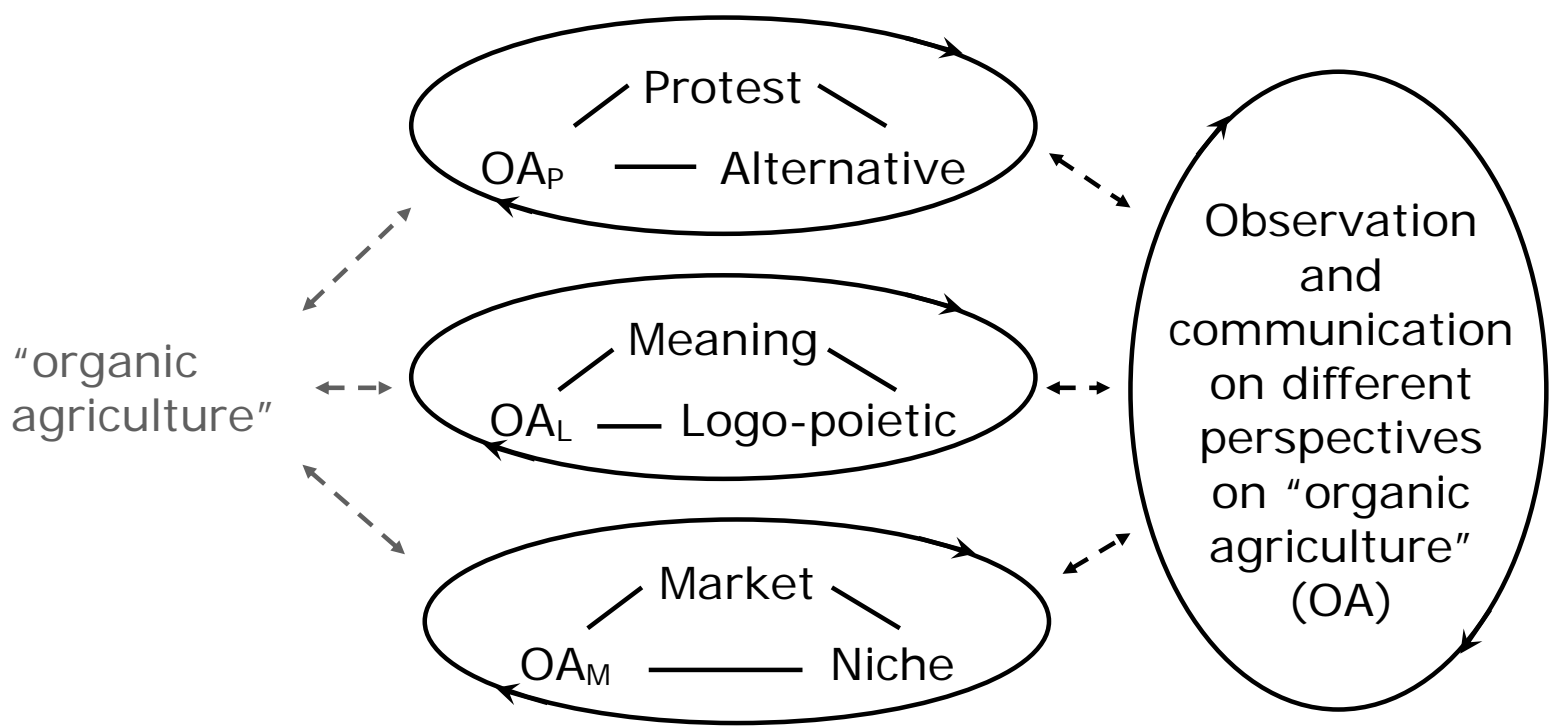

Figure 2.

A polyocular view of organic agriculture, showing a second order process of polyocular observation and communication on three perspectives on the dynamical object of 'organic agriculture'. 
Table 1: Three levels of cognitive context

\begin{tabular}{l|l|l} 
Level of context & Description & Examples \\
\hline \hline$\| \begin{array}{l}\text { Observational } \\
\text { context }\end{array}$ & $\begin{array}{l}\text { Conceptual and technological } \\
\text { tools for observing the } \\
\text { phenomenon }\end{array}$ & $\begin{array}{l}\text { Cognitive schemata, concepts, } \\
\text { models, instruments, labs, etc. }\end{array}$ \\
\hline $\begin{array}{l}\text { Motivations for observing the } \\
\text { Intentional context } \\
\text { phenomenon }\end{array}$ & $\begin{array}{l}\text { Values, principles, aims, goals, } \\
\text { problems, etc. }\end{array}$ \\
$\begin{array}{l}\text { Those who want to observe the } \\
\text { phenomenon }\end{array}$ & $\begin{array}{l}\text { Particular social groups, organi- } \\
\text { sations, 'the sponsor', 'science' }\end{array}$ \\
\hline
\end{tabular}

Source: modified after Alrøe and Kristensen (2002)

i We use the colloquial term 'move' here because we need a broad concept of change, dynamics, development and influence, which does not import unwanted connotations from more specific and well established approaches, and which therefore allows for a fresh, less restricted reflexiveness on continuity and change in organic agriculture. The term 'move' can be understood in both a passive and an active sense. It refers to different kinds of growth, developmental trends and other aspects of the dynamics of organic agriculture, but it also refers to how the course of organic agriculture is influenced in various ways, such as the internal guidance by values and principles, by practical experiences, and by options and restrictions that inherent in the organic systems and their local context; the external influence from market forces and other general economic and societal environments; and the governance of organic agriculture through organic regulations and other policy environments.

ii In relation to the main questions, the Organic Revision project also poses more specific questions concerning contested issues in relation to the future dynamics and governance of organic agriculture: Based on the efforts to harmonise standards to enable free trade, is there a conflict between common rules and local adaptations of organic practices? In light of the derogations to the EU organic regulations, what non-organic inputs are really necessary? And 'necessary' in what sense, to realise the organic values or to compete on the market? And what, by the way, does 'organic' mean here? Says who? In what ways is growth in organic agriculture dependent on the use of conventional inputs and systems? And when is this a problem? Intensification is a key strategy to compete on the market, but when is increased efficiency and specialisation problematic? Localness is one of the counter strategies to globalisation and functional differentiation, but: How local is local? Is spatial nearness all that matters, and where does it matter at all? For further information, see <http://www.organic-revision.org $>$.

iii Ronald N. Giere $(2003,2006)$ promotes a related approach that is more narrowly concerned with the perspectival nature of scientific knowledge, using colour vision as a key example, and he usefully places his 'perspectivism' in the context of the dispute between realism and constructivism in philosophy of science. Rueger (2005) gives a more technical, model-theoretical analysis in the same spirit.

iv Peirce's 'immediate object' is thus akin to what is more loosely called 'epistemic object' in recent social research that focuses on practice (e.g., Knorr Cetina, 2001: 181ff).

v For example, when organic agriculture came under governmental regulation and control in Denmark in the late 1980s, it was suggested to form a new organic association with a new name and a new, protected, brand (Christensen, 1998: 21). 